\title{
Stress at work and risk of myocardial infarction
}

\author{
Töres Theorell
}

National Institute for Psychosocial Factors and Health, Box 60 210, S-10401 Stockholm, Sweden.

For people in the urbanized part of the world, work is important not only for financial support and survival but also for the development of self-esteem. Those who have a stimulating job also get more contacts, develop more skills and improve their ability to cope with difficult situations. Neighbours look at those people with considerable appreciation and their children talk with pride about them. What I am trying to say is that the psychosocial work situation affects the person not only while he/she works but also during leisure time and possibly also after retirement. Furthermore, it may affect the next generation since children may learn from their parents not only diet and smoking habits - both of which may be influenced by the psychosocial working environment - but also psychosocial life strategies, some of which are heavily dependent on the psychosocial work environment.

The psychosocial work environment could influence risk of myocardial infarction, either via accepted risk factors or more directly via neuro-hormonal mechanisms. In the first case, a boring job requiring constant attention may make it 'necessary' for some workers to smoke in order to stay sufficiently alert and some job environments create social pressure promoting the smoking habits. Also, a boring job may contribute to a feeling that life is not worth much anyway. Why prolong it by adapting a healthy life style? In the second case, adverse conditions may induce constant mobilization of energy. This may induce a 'catabolic' situation. If this is not balanced by 'anabolic' restoring activities, the condition of the myocardium may deteriorate and this may facilitate the onset of a myocardial infarction.

Which psychosocial working environments are adverse to the heart? During the first phase of research, everyone took for granted that 'adverse stress' was synonymous with excessive work - either a rushed tempo or long working hours. Later research has pointed out that excessive working may not be dangerous. According to the hypothesis proposed by Karasek (1979), danger arises when the demands are excessive and at the same time decision latitude or the utilization of skill is poor. However, when the number of working hours per week is extremely high (total work week $>70-80$ hours), we should expect in-

Correspondence: T. Theorell, M.D. creased risk, because in such a position the person is likely to lose control both of the psychosocial situation and the physiological balance, as has been shown by Rissler \& Elgeroth (1978) and previously in the 1950s by Friedman et al. (1958). The classical study of the Bell Telephone Company verified that men who worked full-time and at the same time went to night college were more likely than others to die sudden coronary deaths while doing so (Hinkle, 1974).

Rather early, some researchers reached the conclusion that rushed tempo or moderately long working hours were inconsistent predictors of risk. For instance, Kittel et al. (1980) made the observation in Belgium that the incidence of myocardial infarction was higher in a cohort of privately employed bank clerks than it was in a cohort of bank clerks working for the government. Somewhat longer working hours in the private banks was not the only factor of potential importance - employment insecurity, for instance, could also have been important.

In our own later research, we have focused on the following potentially preventable factors: rushed tempo or long working hours, low authority over decisions or utilization of skill, shift work, combinations of rushed tempo and physical strain and social support at work.

In two different register studies, we have utilized the three digit occupational title for making a classification of psychosocial characteristics (Alfredsson et al., 1983). Our national surveys were utilized for this. The proportion of men and women, respectively, reporting 'rushed tempo', 'monotony', 'no possibility to learn new things', etc. in each occupation was calculated. Then, for instance, all bakers in the study (who were not the same people as those included in the classification survey) were assigned to the group considered to be more exposed ('upper half' of the occupations) or less exposed depending on the relative position of bakers in relation to other occupations. In the first study all men who had suffered a myocardial infarction before the age of 65 (who died or survived) during a certain two years and lived in a certain area of greater Stockholm constituted the case groups (Alfredsson \& Theorell, 1983). Non-cases were matched with regard to age and living area. Job title was searched for in the census which took place five years before the onset of illness. Age-adjusted relative risks of belonging to the

(C) The Fellowship of Postgraduate Medicine, 1986 
case group were calculated for a number of psychosocial job characteristics.

The same calculation was made for combinations of high tempo and some other characteristics. In the other study all working men and women in five counties constituted the studied cohort (Alfredsson et al., 1985). Job title was identified in the census in 1976 and a one-year follow-up was made in the hospital registers. Cases of myocardial infarction were identified. Several confounding tests were performed (living area, marital status, employed/self-employed status, number of children, proportion of smokers and prevalence of heavy lifting in the occupation etc.). Only associations which were not 'explained away' by such confounders are shown (see Table I).

In both studies typical shift-work occupations had higher myocardial infarction incidences than other jobs. 'Hectic' occupations did not have elevated incidences, but 'hectic' occupations with few opportunities to learn new things had the highest incidences in both studies. For women (only in the second study) the most adverse combination was 'hectic' and 'monotonous'. The data indicated that a 'hectic tempo' not only added to risk but also interacted with 'boring' characteristics in producing excess risk. In the first study we also studied combinations of hectic tempo and physical strain and found a number of significant associations despite the fact that none of the factors separately had a statistically significant explanatory value. In general the findings were stronger before the age of 55 (only studied in men).

These findings are consistent with a retrospective register study in the USA by Karasek et al. (1982) as well as a prospective mortality study by another group (Shaw \& Riskind, 1983). They are also in agreement with studies of individuals who were interviewed about their own work environment and then followed with regard to heart disease, symptoms, in Sweden (Karasek et al., 1981), or with regard to development of coronary hear: disease in the US (Haynes, 1985). Johnson (1985), finally, has studied a large cohort of men and women who were interviewed about their work and then followed-up for 5 years with regard to

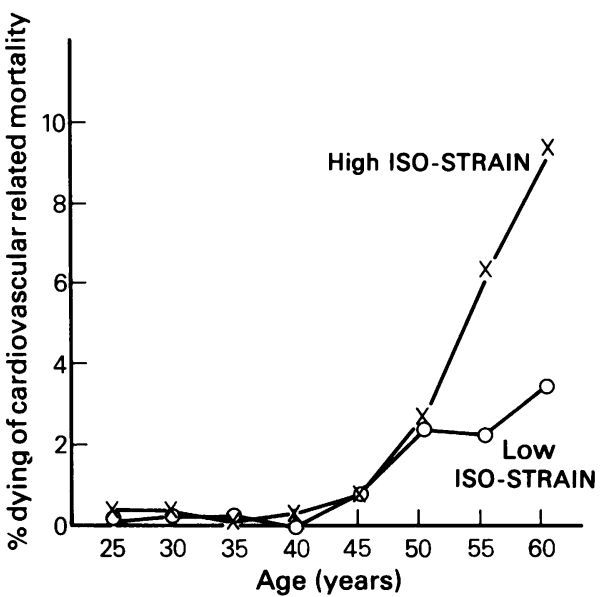

Figure 1 Cardiovascular mortality (arteriosclerotic and cerebrovascular) during a 5 year follow-up of 4,242 bluecollar men randomly selected in Sweden and interviewed in 1976-77 while they were working. Three work dimensions, demand, control and support at work, were constructed. After transformation to Z-scores (high score $=$ bad condition), all three were multiplied into the ISO-STRAIN score. High ISO-STRAIN = upper tertile; Low ISO-STRAIN = lower tertile. The difference between the cardiovascular mortality in the two groups is statistically significant (Johnson, 1985).

coronary death. In this study, excessive psychological demands, low decision latitude and poor social support at work all contributed to the prediction of heart disease (cross-sectional study) and also interacted significantly with one another in the prediction. In the follow-up, the group with a bad combination (calculated from a multiplication of Z-scores of all the three dimensions; the upper tertile was compared with the lower one) (adverse 'ISO-STRAIN') showed a higher cardiac mortality than the group with a good combination, although the prediction was statistically

Table I Relative risk of being hospitalized for a myocardial infarction during a one-year follow-up of all working men and women in five counties in Sweden $(n \approx 1.000 .000)$ in relation to type of occupation classified according to a national survey

Type of occupation

$$
\text { Men 20-64 Men 20-54 Women 20-64 }
$$

$\begin{array}{llll}\begin{array}{l}\text { Hectic and } \\ \text { non-learning }\end{array} & 1.28(1.09-1.48) & 1.57(1.25-1.94) & \text { n.s. } \\ \begin{array}{l}\text { Hectic and } \\ \text { monotonous }\end{array} & 1.18(1.02-1.35) & 1.53(1.23-1.87) & 1.64(1.12-2.33) \\ \text { Shift work } & 1.15(1.04-1.26) & 1.30(1.12-1.51) & 1.52(1.19-1.91)\end{array}$


Table II Systolic blood pressure (SBP) outside and at work (men only)

\begin{tabular}{lccccc}
\hline & Mean age & $n$ & $\begin{array}{c}\text { Mean } \\
\text { decision } \\
\text { latitude }\end{array}$ & $\begin{array}{c}\text { Mean SBP† } \\
\text { outside work } \\
\text { (mm Hg) }\end{array}$ & $\begin{array}{c}\text { Mean SBP } \\
\text { at work } \\
\text { (mm Hg) }\end{array}$ \\
\hline Baggage handlers & 43.7 & 19 & 8.8 & 129 & $137^{* *}$ \\
Symphony musicians & 40.5 & 26 & 9.0 & 125 & $132^{* *}$ \\
Waiters & 44.7 & 12 & 10.1 & 124 & $127 \ddagger$ \\
Physicians & 41.3 & 16 & 13.4 & 125 & $126 \ddagger$ \\
At least three measurements for each person and condition. & & & \\
\hline
\end{tabular}

${ }^{* *} P<0.01$ (compared with outside work); $\ddagger$ not significant; $\nmid$ mean of individual means.

significant only among blue-collar men (Johnson, 1985) (Figure 1).

A study of early stage mainly asymptomatic hypertension in 28 year old men using LISREL analysis indicated that elevated systolic blood pressure at rest could be predicted by a pathway from poor social stimulation (type of job not giving opportunity to learn new things as well as poor social network in general) to elevated plasma adrenaline at rest and then to high systolic resting blood pressure. Another was from poor employment security to overweight and then to high systolic resting blood pressure. In the same study we could show that blood pressure elevation (self-triggered measurements) in the job situation was much more marked among subjects with a high blood pressure already at age 18 who were now working in 'strain' occupations such as waiter, cook and driver.

In an on-going study we have compared self-monitored blood pressures at work and during leisure time among men from the age of 25 to 61 (means 40-44) in four different occupations. The two occupations with low decision latitude (baggage handlers and symphony musicians) have much more blood pressure elevation at work than the group with a high decision latitude (physicians) (Table II).

A retrospective case-control study of 55 men with myocardial infarction before age 45 examined within 3-6 months and a sample of 99 age-matched noncases living in the same areas in greater Stockholm included all clinical risk factors, type A behaviour (Jenkins Activity Survey) and psychosocial work environment variables. The results (by multiple regression analysis) indicated that LDL/HDL ratio, smoking, family history, monotony at work, alcohol and education were the only significant independent predictors of case-control status. Thus, it seems that a boring job may facilitate the development of an early myocardial infarction, even when other relevant factors have been controlled (Orth-Gomer et al., 1985).

Some of our findings may be explained as mere social class phenomena. However, in the Swedish and
American studies, social class has not 'explained away' the association.

In Sweden there is a great interest in the work environment from a preventive standpoint. OrthGomer (1983) published a study of improved shiftwork cycles which indicated that sleep as well as triglycerides and blood pressure levels improved as the shift cycle improved. The experience in the Volvo factories of making the work content more interesting and more socially stimulating by making a group of workers responsible for a large part of the car have been encouraging. Our results which indicate that 'non-learning' and boring jobs are dangerous may even indicate that these kinds of job enrichments may reduce myocardial infarction risks.

\section{Psychological factors}

Individual psychological factors may modify the effect of the environment. We believe that alexithymia inability to describe emotions - may be a fruitful concept. In our study of 28 year old men with high blood pressure, a group with substantially elevated risks of developing early coronary heart disease, a structural interview was made in order to describe men's ability to identify in themselves, joy, sorrow, anger and anxiety. The interviewers knew nothing about the subjects' blood pressures (most of the subjects were asymptomatic) and the interviews were recorded to allow an independent rating of various aspects of alexithymia. The main hypothesis - inability to differentiate feelings is associated with elevated blood pressure at rest - was verified for diastolic blood pressure. Inability to describe sorrow on a general level and a low frequency of joy were significantly more frequent traits in the men with high blood pressure at rest than among other men (Theorell et al., 1984a, b). These observations need to be repeated. A low score of verbal aggression - a score calculated from a self-administered questionnaire introduced by 
Daisy Schalling in Stockholm - was also significantly more common in the men with high blood pressure than in other men.

Another hypothesis tested in the study of young men was that a high level of psychological motivation for work would be associated with high blood pressure. An independent rater classified answers to the question: 'Why do you work?' into 'Mainly psychological motivation' and 'other'. 'Mainly psychological' was significantly more common among the hypertensive men compared to the others.

Thus, our analyses of young men with elevated future risk indicate that these men have a combination of a high level of psychological work motivation and several alexithymia traits. We could assume that men who show these traits are likely not to complain about adverse job conditions. This may explain why many researchers find that hypertensive asymptomatic men do not report job stress. Also, they would be likely to not formulate problems and, thus, not facilitate necessary changes of adverse conditions at work when they arise. Instead, they would be likely to develop long-lasting psychophysiological tensions. These theories have to be tested in other studies.

\section{Conclusions}

In conclusion, our data indicate that job content and structure may be important in the pathogenesis of myocardial infarction but also that certain individual traits which are common in all occupations may modify the reactions to adverse conditions. The experience in Scandinavia indicates that it is possible to improve job conditions and that this may reduce heart disease risk.

\section{References}

ALFREDSSON, L., KARASEK, R.A. \& THEORELL, T. (1982). Myocardial infarction risk and psychosocial work environment: An analysis of the male Swedish working force. Social Science and Medicine, 16, 463.

ALFREDSSON, L. \& THEORELL, T. (1983). Job characteristics of occupations and myocardial infarction risk - effect of possible confounding factors. Social Science and Medicine, 17, 1497.

ALFREDSSON, L., SPETZ, C.-L. \& THEORELL, T. (1985). Type of occupation and near future hospitalization for myocardial infarction and some other diagnoses. International Journal of Epidemiology, 14, 378.

FRIEDMAN, M., ROSENMAN, R.H. \& CARROLL, V. (1958). Changes in the serum cholesterol and blood clotting time in men subjected to cyclic variation of occupational stress. Circulation, 17, 852.

HAYNES, S. (1985). Job strain and risk of coronary heart disease - findings in the Framingham Study. Personal Communication

HINKLE, L.E. (1974). The effect of culture change, social change and changes in interpersonal relationships on health. In Stressful Life Events - Their Nature and Effects, Dohrenwend, B.S. \& Dohrenwend, B.P. (eds). Wiley: New York.

JOHNSON, J. (1985). The effects of control and social support on work-related strain and adverse health outcomes. Mimeograph. Dept. of Social Psychology of Work, University of Stockholm.

KARASEK, R.H. (1979). Job demands, job decision latitude and mental strain. Implications for job redesign. Administrative Science Quarterly, 24, 285.

KARASEK, R., BAKER, D., MARXER, F., AHLBOM, A. \& THEORELL, T. (1981). Job decision latitude, job demands and cardiovascular disease: A prospective study of
Swedish men. American Journal of Public Health, 71, 694. KARASEK, R.A., SCHWARTZ, J. \& THEORELL, T. (1982). Stress at work and cardiovascular disease. Mimeograph. Dept. of Industrial Engineering and Operations Research, Columbia University, New York.

KITTEL, F., KORNITZER, M. \& DRAMAIX, M. (1980). Coronary heart disease and job stress in two cohorts of bank clerks. Psychotherapy and Psychosomatics, 34, 110.

ORTH-GOMER, K. (1983). Intervention on coronary risk factors by adapting a shift-work schedule to biologic rhythmicity. Psychosomatic Medicine, 45, 407.

ORTH-GOMER, K., AHLBOM, A. \& THEORELL, T. (1980). Impact of pattern A behaviour on ischaemic heart disease when controlling for conventional risk indicators. Journal of Human Stress, 6, 6.

ORTH-GOMER, K., HAMSTEN, A., PERSKI, A., THEORELL, T. \& DE FAIRE, U. (1985). Type A behaviour, education and psychosocial work characteristics in relation to ischaemic heart disease. A case control study of myocardial infarction patients below age 45. Manuscript. National Institute of Psychosocial Factors and Health, Stockholm.

RISSLER, A. \& ELGEROTH, A. (1978). Stress reactions during overtime work (Swedish). Report no. 23, Dept. of Psychology, University of Stockholm.

SHAW, J.B. \& RISKIND, J.H. (1983). Predicting job stress using data from the position analysis questionnaire. Journal of Applied Physiology, 68, 253.

THEORELL, T., ALDREDSSON, L., KNOX, S., PERSKI, A., SVENSSON, J. \& WALLER, D. (1984). On the interplay between socioeconomic factors, personality and work environment in the pathogenesis of cardiovascular disease. Scandinavian Journal of Work and Environmental Health, $10,373$.

THEORELL, T., FLODERUS, B. \& LIND, E. (1975). The 
relationship of disturbing life-changes and emotions to the early development of myocardial infarction and other serious illnesses. International Journal of Epidemiology, 4, 281
THEORELL, T., KNOX, S., SVENSSON, J. \& WALLER, D. (1984). Psychosocial work environment and blood pressure (Swedish). Report to the Work Environment Fund (80/3960), Stockholm, 1984. 